\title{
Response of Smoke Detectors to Monodisperse Aerosols
}

\author{
George W. Mulholland* \\ National Bureau of Standards, Washington, D.C. 20234 \\ and \\ Benjamin Y. H. Liu \\ Department of Mechanical Engineering, University of Minnesota, Minneapolis, Minnesota 55455
}

November 28, 1979

\begin{abstract}
The response of three light scattering smoke detectors (photo-electric detectors) and three ionization smoke detectors were determined as a function of particle size and concentration for nearly monodisperse dioctyl phthalate aerosol $\left(\sigma_{g}=1.25\right)$. The range in particle diameter was about 25 to $1(0.05$ to $1.3 \mu \mathrm{m})$ while the range in concentration was about two orders of magnitude $\left(2 \times 10^{4}\right.$ to $3 \times 10^{6}$ particles $\left./ \mathrm{cm}^{3}\right)$. Detailed descriptions of the aerosol generation system and the smoke detector test chamber are given. The responses of the ionization detectors were found to have a nearly linear dependence on particle size as predicted by Hosemann's theory. The ionization detectors responded to the smallest particles generated. The light scattering detectors did not respond to particles with diameters of $0.1 \mu \mathrm{m}$ or less and were found to have a strong dependence on particle size, the fourth to fifth power of particle diameter, for particle sizes less than $0.5 \mu \mathrm{m}$. It was found that ionization detectors generally had a higher response than the light scattering detectors to particles smaller than $0.3 \mu \mathrm{m}$, which size range is typical of flaming combustion, and that the light scattering detectors had a higher response to particles larger than $0.3 \mu \mathrm{m}$, which size range is typical of smoldering combustion.
\end{abstract}

Key words: Aerosol generators; aerosols; detector sensitivity; fire detectors; ionization detectors; light scattering detectors; monodisperse aerosols; particle size; photo-electric detectors; smoke detectors.

\section{Introduction}

The term smoke detector refers to a device that produces an audible alarm signal as a result of the presence of combustion products (smoke). Most smoke detectors in American residences detect the presence of the particulate component of the combustion products rather than the gaseous component. The focus of this paper is on the response characteristics of such particulate or smoke aerosol detectors as a function of the smoke aerosol properties and, in particular, the paper is concerned with the ionization type and light scattering type smoke aerosol detectors. The term smoke detector will be used in this paper to mean smoke aerosol detector.

-Visiting scientist at the University of Minnesota where research was performed. Current address: Center for Fire Research, National Engineering Laboratory, NBS.
The two most important aerosol properties affecting the performance of these detectors are the concentration of the smoke aerosol and the particle size. There is a lack of quantitative data regarding the dependence of smoke detector performance on these properties because of the difficulty involved in reproducibly generating a smoke aerosol of fixed size coupled with the complex measurement problem of characterizing the aerosol. Both of these difficulties are apparent in the studies by Hosemann [1] ${ }^{1}$ and Scheidweiler [2] of the response of an ionization type detector as a function of relative particle number concentration. First, as pointed out by Lee and Mulholland [3], the size distribution of the aerosol changes as a result of the phenonmenon of particle coagulation for recirculating aerosol generators such as those used by Hosemann and Scheidweiler. Second-

\footnotetext{
' Figures in brackets indicate literature references at the end of this paper.
} 
ly, the value of optical density per path length was used as a relative measure of the number concentration, but this indirect method is only semi-quantitative for the case where the size distribution is changing with respect to time.

In contrast to the recirculating systems used before, this study utilizes a steady state aerosol generator which allows independent control of particle size, from $0.05 \mu \mathrm{m}$ to about $1.3 \mu \mathrm{m}$, and particle concentration, from $10^{4}$ to $10^{6}$ particles $/ \mathrm{cm}^{3}$. The pneumatically driven monodisperse aerosol generator used in this study was adapted from a design used in the field of air pollution monitoring. Quantitative measurements of the particle number concentration and size distribution were obtained using an electrical aerosol analyzer and an optical particle counter. Again, these instruments have been routinely used for monitoring particulate levels in polluted environments but have not been applied widely to smoke aerosol studies. The performance of the aerosol generator and the accuracy of the aerosol measurements are treated in some detail in sections 3 and 4.

The major findings of this study are the detector outputs of six smoke detectors, three light scattering types and three ionization types, to nearly monodisperse aerosols. The six detectors studied are described in section 2 of the paper. It must be stressed that this study does not attempt to evaluate the overall performance of these detectors. The performance of a smoke detector depends on many factors besides its inherent particle size response characteristics. The entry characteristics of the detector is a very important factor as well as the reliability of the unit over a long period of time. While particle size and concentration are thought to be the two most important aerosol properties affecting detector response, the refractive index of the aerosol will affect the light scattering type detectors, the particle charge may affect the ionization detector, and the shape of the aerosol is expected to affect both types of detectors.

Sections 6 and 7 contain the first experimentally determined detector size response curve and a discussion of the curves in light of smoke detector theory.

\section{Description of smoke detectors}

The light scattering type detector and the ionization type detector operate on fundamentally different physical principles. A brief explanation of these mechanisms is given followed by a description of each of the three detectors of that respective type. Also the key parameters affecting the inherent sensitivity of the detectors are enumerated and approximate values for these parameters for each detector are tabulated.

\subsection{Light scattering detector}

As the name suggests, the scattering of light by the smoke particles is the basic physical phenomenon for the ilght scattering type detectors. Figure 1 is a schematic of such a smoke detector. The lens and aperture produce a well collimated light beam. The inner surface of the scattering chamber is blackened to prevent reflected light from entering the photocell. With no smoke present there is no light reaching the photocell. As smoke particles enter the detector, they scatter light into the photocell and at a preset signal strength the alarm is triggered.

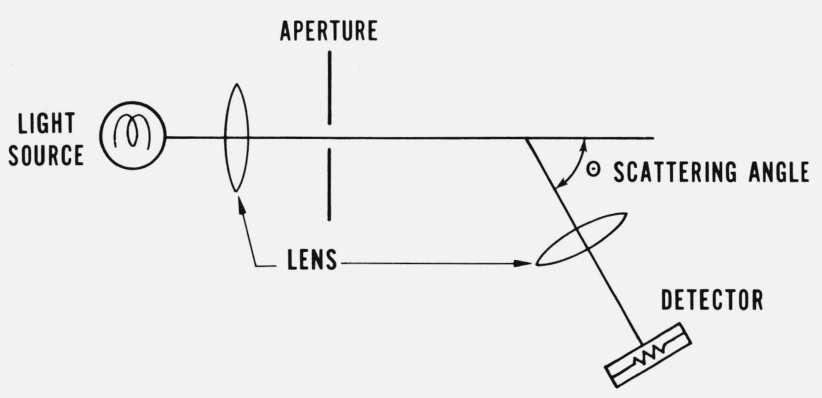

FIGURE 1. Schematic of light scattering smoke detector.

The intensity of light scattered from the smoke particle depends on the particle size and shape, the refractive index, and the spectral distribution of the light source. Except for very small particles, the scattering intensity is largest for small scattering angles $(\theta$ small in fig. 1$)$. Other parameters affecting the detector signal are the spectral response of the photocell and the scattering volume, which is defined by the dimension of the light beam and the collection optics of the detector.

The basic design parameters of the three light scattering detectors, identified as $\mathrm{S}-1, \mathrm{~S}-2$, and S-3, are given in table 1 . The three detectors encompass a wide range of scattering angles varying from near forward $\left(21^{\circ}\right)$ to $90^{\circ}$. They also encompass a wide range of light sources including an incandescent lamp, a red light emitting diode (LED), and an infra-red LED. A qualitative discussion of the effects of scattering angle and the wavelength of the light source will be presented in the discussion section. A quantitative discus-

TABle 1: Design Parameters for Light Scattering-Type Detectors.

\begin{tabular}{c|c|c|c}
\hline \hline Detector & $\begin{array}{c}\text { Light } \\
\text { Source }(\eta \mathrm{m})\end{array}$ & $\begin{array}{c}\text { Scattering } \\
\text { Angle }\end{array}$ & $\begin{array}{c}\text { Scattering } \\
\text { Volume }\left(\mathrm{cm}^{3}\right)\end{array}$ \\
\hline S-1 & $\begin{array}{c}\text { tungsten lamp } \# 755 \\
\text { color temperature } \\
\text { about } 2000^{\circ} \mathrm{K}\end{array}$ & $60^{\circ}$ & 0.5 \\
\hline S-2 & $\begin{array}{c}\text { LED }^{\mathrm{a}} \\
940\end{array}$ & $21^{\circ}$ & 0.5 \\
\hline S-3 & $\begin{array}{r}\text { LED } \\
690\end{array}$ & $90^{\circ}$ & 1.1 \\
\hline
\end{tabular}

a LED stands for light emitting diode. 
sion would require more detailed information regarding the design parameters such as the full spectral response of the photocells.

\subsection{Ionization detector}

The principle behind the ionization type smoke detector is somewhat more subtle than that for the light scattering type detector. The basic process is the attachment of ions to smoke particles. The ions are produced by the interaction of $\alpha$-radiation with the molecules in air. For the three detectors studied, americium with a half-life of 433 years was used as the source of the $\alpha$-particles. In the absence of smoke the positive ions move toward one electrode while the negative ions move in the opposite direction thus producing a small electrical current on the order of picoamps. A schematic of such a detector is given in figure 2. This current is reduced by the presence of smoke particles because of the capture of the ions by the smoke particles. The electric field inside the detector is not strong enough to collect the charged smoke particles, which have a much lower electrical mobility than the ions. At a preset minimum current the detector will go into alarm.

The performance of an ionization detector depends on the geometry and dimensions of the ionization chamber, the nature and strength of the radioactive source, and the voltage. Atmospheric conditions also affect the ionization detector's performance. The atmospheric pressure will affect the

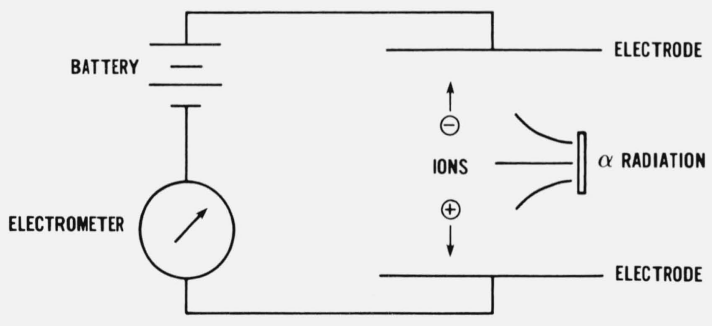

FIGURE 2. Schematic of single chamber ionization smoke detector. penetration distance of the $\alpha$-particles and the humidity will affect the mobility of the ions produced through attachment of water molecules to the positive ions. These atmospheric effects are partially eliminated for the two dual chamber detectors, R-2 and R-3, considered in this study. In the dual chamber configuration, one chamber, which remains free of smoke, acts as a reference in compensating for changes in the atmospheric conditions.

The various design parameters for the three detectors are listed in table 2. Detectors R-2 and R-3 are rather similar in design. Two differences are the flatter shape and smaller chamber volumes for R-3 compared to R-2. Detector R-1 is a single chamber detector with a much smaller source strength and smaller chamber size.

The source strength given in table 2 is somewhat misleading. The actual $\alpha$-radiation emitted per second is much smaller than the number of americium atoms disintegrating per second because of the attenuation of the $\alpha$-particles in penetrating the americium substrate. For a detector similar to $\mathrm{R}-2$ it was found that the actual $\alpha$-particle production was on the order of four orders of magnitude smaller than the indicated activity. A $9 \mu \mathrm{Ci}$ source was found to correspond to $12 \alpha$ particles per second or $3.2 \times 10^{-4} \mu \mathrm{Ci}$ [4].

\section{Aerosol generation system}

Since monodisperse aerosol generation techniques are not widely used in the field of smoke detector technology, a detailed description of the aerosol generation system will be given. Basically the system consists of four parts: an aerosol generator, an evaporation-condensation column, conditioning equipment, and a smoke detector test chamber. A nebulizer generates a polydisperse aerosol which is then made monodisperse by an evaporation-condensation column. Next the aerosol passes through conditioning equipment which controls the aerosol concentration, humidity, and charge, after which it enters the smoke detector test chamber. A schematic of the overall design is given in figure 3 . The remainder of this section provides a detailed description of the system.

TABle 2: Design Parameters for Ionization-Type Smoke Detectors.

\begin{tabular}{|c|c|c|c|c|}
\hline Detector & $\begin{array}{c}\alpha \text {-Source } \\
\text { Strength }(\mu C i)\end{array}$ & $\begin{array}{l}\text { Chamber } \\
\text { Geometry }\end{array}$ & $\begin{array}{c}\text { Chamber } \\
\text { Volume }\left(\mathrm{cm}^{3}\right)\end{array}$ & Voltage \\
\hline R-1 & 1 & cylinder & 17 & 15 \\
\hline $\mathrm{R}-2$ & $\begin{array}{l}9 \\
6 \\
\end{array}$ & $\begin{array}{l}\text { capped cylinder; } \\
2: 1 \text { width to height (dual) }\end{array}$ & $\begin{array}{r}250 \\
60 \\
\end{array}$ & 24 \\
\hline $\mathrm{R}-3$ & $13.4^{\mathrm{a}}$ & $\begin{array}{l}\text { shallow cylinder; } \\
4: 1 \text { width to height (dual) }\end{array}$ & $\begin{array}{l}27 \\
27\end{array}$ & 24 \\
\hline
\end{tabular}

a Total of $13.4 \mu \mathrm{Ci}$ for both sources in the dual chamber 


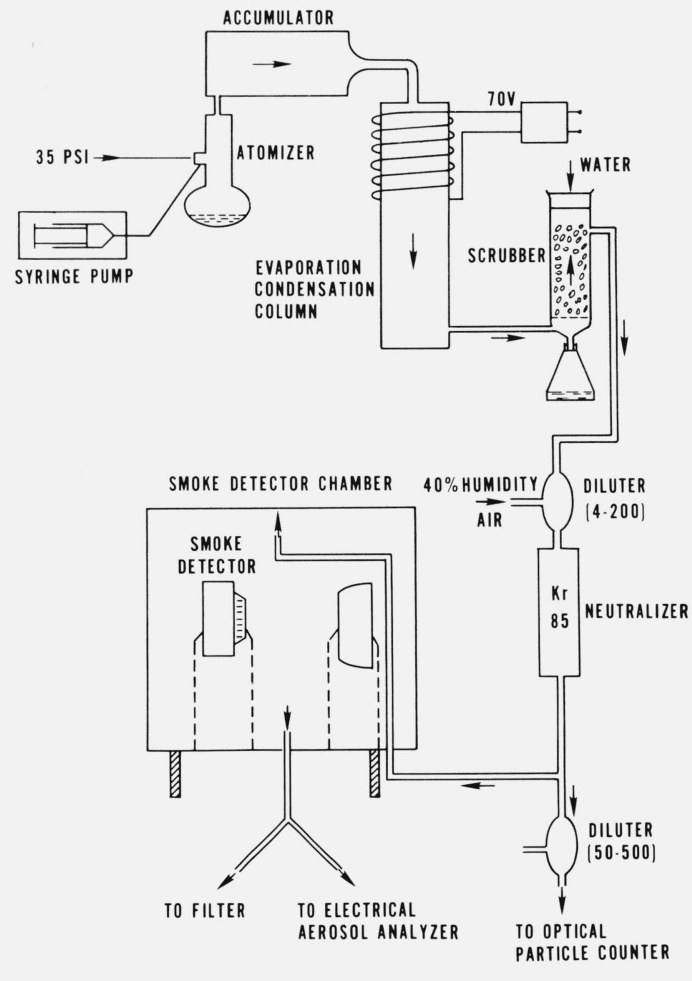

FIGURE 3. Monodisperse aerosol generation system.

\subsection{Aerosol generator}

A pneumatic nebulizer with a constant liquid feed from a syringe pump was used to generate the aerosol. The instrument is similar in design to that described by Liu and Lee (5) and was purchased commercially (Model 3075, Thermosystems, Inc.). ${ }^{2}$ The nebulizer produces a polydisperse aerosol by spraying a solution of isopropanol and Bis (2-ethylhexyl) phthalate, which is better known by the name dioctyl phthalate or DOP. The DOP is an oily viscous liquid by itself. The alcohol rapidly evaporates from the generated droplets leaving pure DOP droplets.

From the nebulizer, the aerosol passes through a 2000 $\mathrm{cm}^{3}$ accumulator at a flow rate of $67 \mathrm{~cm}^{3} / \mathrm{s}$. The accumulator reduces a periodic variation in aerosol production caused by the syringe pump from \pm 10 to \pm 3 percent.

\subsection{Evaporation-condensation column}

Next the aerosol passes through an evaporation-condensation column, which consists of a glass tube the upper half of which is heated by an electrical tape heater. It is similar

\footnotetext{
2 Certain commercial equipment, instruments, and materials are identified in this paper in order to adequately specify the experimental procedure. In no case does such identification imply recommendation or endorsement by the National Bureau of Standards of the University of Minnesota, nor does it imply that the material or equipment identified is necessarily the best available for the purpose.
}

in design to that described by Liu and Lee (5) and was purchased commercially (Model 3072, Thermosystems, Inc.). A small amount of anthracene was added to the DOP/ alcohol solution $\left(0.1 \mathrm{~g}\right.$ anthracene per $1000 \mathrm{~cm}^{3}$ of DOP) prior to being nebulized. The DOP droplets first evaporate in the heated column supposedly leaving anthracene nuclei. The DOP vapor subsequently condenses on the nuclei to form uniform size droplets in the lower half of the tube, which is cooled by free convection. Since the number of nuclei depends primarily on the number of droplets produced by the nebulizer, the generator output is approximately constant in terms of number concentration; however, the particle size may be varied between $1.3 \mu \mathrm{m}$ and $0.05 \mu \mathrm{m}$ by varying the concentration of DOP dissolved in the isopropanol (pure DOP to $0.013 \%$ volume DOP relative to the solution volume respectively). Most of the DOP condenses on the particles because of the low DOP vapor pressure at ambient conditions. The approximate particle sizes corresponding to the solution concentrations are given in table 3. The overall performance of the generator will be discussed in section 6 .

TABLE 3: Particle Size versus Solution Concentration

\begin{tabular}{ccc}
\hline \hline $\mathrm{a}$ & $\mathrm{b}$ & $\mathrm{c}$ \\
\hline Nominal $D_{\mathrm{g}}(\mu \mathrm{m})$ & Measured $D_{\mathrm{g}}(\mu \mathrm{m})$ & Concentration \% \\
\hline 0.05 & 0.046 & 0.013 \\
.1 & .078 & .10 \\
.15 & .14 & .3 \\
.2 & .17 & .67 \\
.3 & .22 & 2.1 \\
.5 & .58 & 8.3 \\
.7 & .73 & 20 \\
1.0 & .86 & 55 \\
1.3 & 1.06 & 100 \\
\hline
\end{tabular}

a) This column refers to the particle size as measured by Liu and Lee.

b) Particle size for solution concentrations of 2.1 percent and less were determined by the EAA; 8.3 percent and greater were determined by the optical particle counter.

c) The concentration refers to $\%$ volume DOP relative to the solution volume.

\subsection{Aerosol conditioning equipment}

In addition to the basic components for the generation of monodisperse aerosols, several subsidiary components were necessary for conditioning the aerosol, including a gas scrubber, diluter, and charge neutralizer. The aerosol generator produces a large quantity of alcohol vapor in addition to aerosol. The alcohol affects the performance of the ionization type detector, perhaps, by decreasing the mobility of the ions produced. It was found for detector R-1 that isopropanol vapor by itself altered the detector output by 40 percent of the maximum output for the detector. The 
alcohol was removed by passing the aerosol stream through a gas scrubber. As illustrated in figure 4, the scrubber consists of a glass tube filled with raschig rings. The water drips down from the top of the scrubber while the aerosol moves up from the bottom. The alcohol vapor diffuses to the surface of the wetted rings and is removed while the aerosol particles, which have a much smaller diffusion coefficient than vapor, pass through the column. A water flow rate of $1.2 \mathrm{~cm}^{3} / \mathrm{min}$. was found to be adequate for removing most of the alcohol vapor for an aerosol flow rate of about 67 $\mathrm{cm}^{3} / \mathrm{s}$.

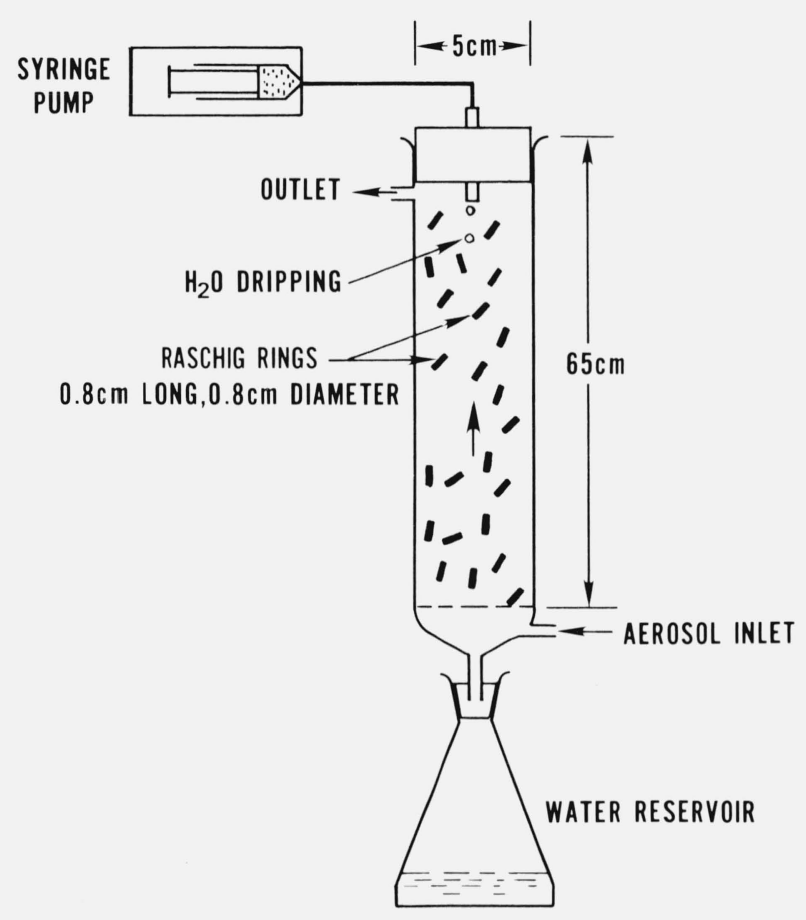

FiguRE 4. Gas scrubber.

The concentration of the aerosol was varied over a range of about a factor of 50 in order to test the linearity of the detector output. The diluter consisted of a turbulent mixing chamber in which the aerosol entered through a restricting orifice while clean dry air entered the chamber perpendicular to the aerosol flow. The dilution ratio was varied both by retaining a controlled fraction of the undiluted aerosol $\left(0-67 \mathrm{~cm}^{3} / \mathrm{s}\right)$ and by controlling the amount of dilution air $\left(0-1667 \mathrm{~cm}^{3} / \mathrm{s}\right)$. This design provides good mixing and a wide dilution range. To minimize corrosion, the two piece diluter was fabricated from stainless steel. A schematic of the turbulent diluter is provided in figure 5. In testing the ionization type smoke detectors, it was found necessary to maintain the humidity of the diluting air at a constant value of 40 percent.

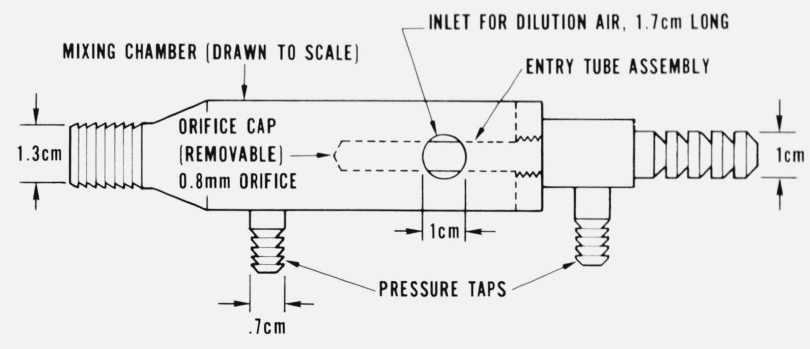

FIGURE 5. Turbulent diluter.

A second diluter was required for measuring the size distribution of the aerosol with the optical particle counter, which operates only at very low concentrations-hundreds of particles per cubic centimeter. Dilution ratios on the order of 50 to 500 were obtained by passing a small portion of the aerosol through a linear flow meter (1.67 to 16.7 $\mathrm{cm}^{3} / \mathrm{s}$ ) and then mixing with approximately $800 \mathrm{~cm}^{3} / \mathrm{s}$ of clean air. An experimental determination of a 90 -fold dilution factor agreed with the predicted value within 10 percent.

The establishment of charge equilibrium is important for testing the ionization-type smoke detectors as well as for the operation of the aerosol monitoring equipment. This was accomplished after diluting the aerosol by passing it through a neutralizer, in which a high concentration of positive and negative ions were produced by a Kr 85 radioactive source (Thermosystems, Inc.).

\subsection{Smoke detector test chamber}

The detector test chamber consists of a cylindrical, plastic bell jar $30 \mathrm{~cm}$ in diameter and $30 \mathrm{~cm}$ high with a volume of $2.2 \times 10^{4} \mathrm{~cm}^{3}$. The aerosol stream enters near the top, center of the chamber, flows upward and then leaves through a copper tube in the lower portion of the chamber as shown in figure 6 . It is important that the aerosol flow not be directed at a detector, since a direct flow may change the response characteristics of an ionization type detector; for example, changing the flow velocity from approximately $.5 \mathrm{~cm} / \mathrm{s}$ to $100 \mathrm{~cm} / \mathrm{s}$ changed the $\mathrm{R}-2$ reading from $0.4 \mathrm{~V}$ to $-0.14 \mathrm{~V}$. At such high flows, the ion velocity in the chamber is controlled by the convective air flow rather than by the electric field in the detector. For a typical electric field strength in a detector of $10 \mathrm{~V} / \mathrm{cm}$ and a positive ion mobility of $1.4 \mathrm{~cm}^{2} \mathrm{~V}^{-1} \mathrm{~s}^{-1}$, one calculates an ion drift velocity of $14 \mathrm{~cm} / \mathrm{s}$. The convective air flow in the detector chamber must be less than the ion drift velocity for the detector to perform properly. Of course, for most detectors the convective flow in the detector chamber is much less than the air flow outside of the chamber because of the flow baffling in the smoke detector chamber entry. Our experiments were 
performed at a flow velocity of about $0.5 \mathrm{~cm} / \mathrm{s}$ to avoid flow effects even with those ionization detectors with little flow baffling.

It was found with the design illustrated in figure 6 that the aerosol concentration was relatively uniform throughout the test chamber. Two detectors may be simultaneously

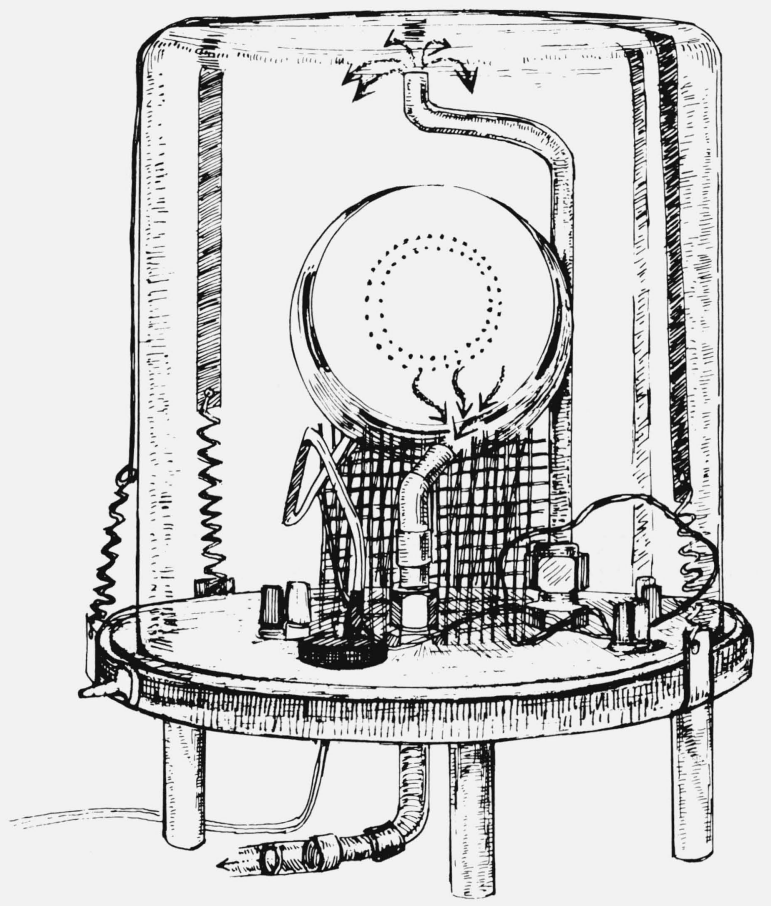

FIGURE 6. Smoke detector test chamber.

tested with the necessary support frames and electrical connections provided. Most measurements were made at a flow rate of $333 \mathrm{~cm}^{3} / \mathrm{s}$ for which the empirically determined equilibration time was found to be about $130 \mathrm{~s}$. The equilibration time is the time required for the aerosol concentration in the test chamber to change from the initial value to the final value. Since the generator varies slightly in output, the final value is considered to be a range of values within \pm 5 percent of the concentration increase. The aerosol concentration was monitored at the outlet of the test chamber with an electrical aerosol analyzer, which has an inherent response time of about $2 \mathrm{~s}$. The $130 \mathrm{~s}$ time is somewhat shorter than the predicted time (180 s) to reach 95 percent of steady state value based on complete mixing.

The time for the detector in the test chamber to respond will be longer than the equilibration time for the test chamber because of the additional times for smoke entry into the detector chamber and for electronic signal processing. Figure 7 illustrates the time lag between the chamber concentration as monitored by the electrical aerosol analyzer and the response of the light scattering type detector S-3, which is known to have a slowly responding photocell. The equilibration time for the test chamber is $130 \mathrm{~s}$ compared to $200 \mathrm{~s}$ for the detector to reach its final value. Again, the final value is considered to be a range of values within \pm 5 percent of the voltage increase.

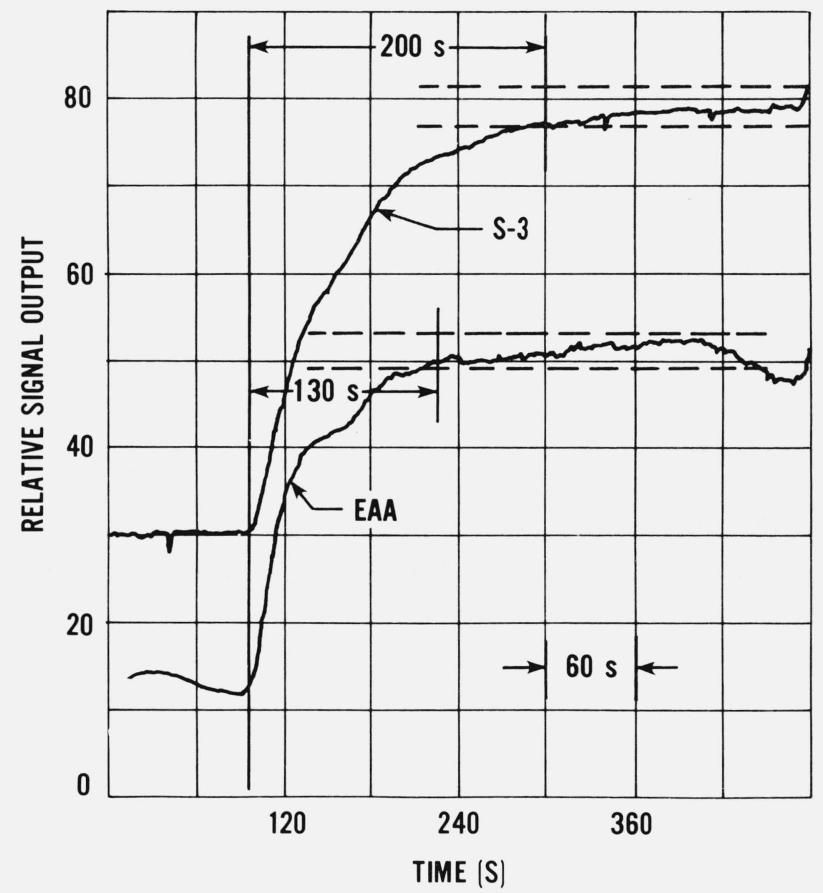

FIGURE 7. The recorder output is displayed for smoke detector $S-3$ and the $E A A$ as the concentration of aerosol in the chamber is increased from one value to a higher concentration.

The dashed lines represent \pm 5 percent of the increase in signal.

\section{Aerosol instrumentation}

After passing through the detector chamber, the aerosol was sampled by several aerosol instruments to determine its size distribution, mass concentration, and number concentration. The instruments used were an electrical aerosol analyzer, an optical particle counter, and a filter gravimetric technique.

The primary instrument used for monitoring the number concentration of the aerosol and the particle size was the electrical aerosol analyzer, EAA (Model 3030, Thermosystems, Inc.), which measures an effective particle size based on electrical mobility. The basic data are the electrical current and condenser voltage which correspond to the particle number concentration and particle size, respectively. The current is monitored for 10 discrete voltages and then expressed in terms of a size distribution by using the data reduction procedure described by Liu et al [6]. 
An independent study by Mulholland et al [7] was made to assess the reliability of the EAA for number and mass concentration measurements. An agreement of better than 30 percent was found for the particle number concentration as determined by the EAA and a condensation nucleus monitor. In our study the EAA was used for measuring the total number concentration for monodisperse DOP aerosols with peak sizes in the range 0.05 to $0.7 \mu \mathrm{m}$. It was found [7] that the particle size determination by the EAA is accurate over a somewhat more restricted size range, $0.3 \mu \mathrm{m}$ and less, than for number concentration determination. Over the size range $0.01 \mu \mathrm{m}$ to $0.3 \mu \mathrm{m}$ it is estimated that the median of the aerosol size as determined by the EAA is within one instrument channel or about \pm 20 percent.

An optical particle counter (Model 220, Royco Instruments) was used for measuring the size distribution for aerosols in the size range 0.4 to $2.4 \mu \mathrm{m}$. In this instrument, a beam of light is focused into a small viewing volume through which the airborne particles pass one at a time. The amount of light scattered from each individual particle at $90^{\circ}$ is measured by a photomultiplier. The pulse heights of the detector signals are monotonically related to the particle size and are sorted and stored in a multichannel analyzer. The optical particle counter coupled with the multichannel analyzer has a high degree of size resolution $(0.03 \mu \mathrm{m} / \mathrm{chan}$ nel) though it has the limitation of saturating at low concentration, on the order of several hundred particles per cubic centimeter. The particle sizing accuracy is estimated to be \pm 10 percent over the size range 0.5 to $2.0 \mu \mathrm{m}$ with the largest uncertainty being for the smallest particles because of the weak scattering signal. The optical particle counter was calibrated using both nebulized monodisperse latex spheres and monodisperse DOP aerosol generated by a Berglund-Liu vibrating orifice generator [8].

The mass concentration of the aerosol was determined by a filter-gravimetric method using a teflon ${ }^{3}$ membrane filter with a $0.5 \mu \mathrm{m}$ pore size and $47 \mathrm{~mm}$ diameter (Fluoropore filter, Millipore Corp.). The flow rate was maintained at a nominal flow of $80 \mathrm{~cm}^{3} / \mathrm{s}$ or $160 \mathrm{~cm}^{3} / \mathrm{s}$ by using critical orifices supplied with the filter holder and the weighing was performed on an electronic microbalance with a sensitivity of $0.1 \mu \mathrm{g}$. The filter gravimetric technique was thought to be the most accurate method for determining concentration; however, our results indicated a systematic error that we attribute to leakage around the polyethylene backing of the laminated teflon membrane filter. The mass concentration may in some cases be 20 to 50 percent low.

\section{Testing procedure}

The use of a stable, steady state generation system, in which DOP aerosol is constantly flowing through the test chamber, is a major difference from the system used by Hosemann and Scheidweiler in which the smoke aerosol accumulates in a closed chamber. A detailed description of the testing procedure follows.

One or two detectors were placed in the detector chamber. The analog outputs from the detectors exposed to ambient air served as the background reading. The evaporation heater was allowed to stabilize for about ten minutes with air flowing through the atomizer but no liquid feed from the syringe pump. The most dilute DOP solution $(0.013 \%)$ was used first in generating the aerosol with the smallest particle size. After another ten minutes of operation with liquid feed from the syringe pump, the aerosol concentration stabilized and readings were taken. The concentration was changed in discrete steps by varying the amount of undiluted aerosol vented and the flow rate of the dilution air. The measurements were always taken in the order of increasing concentration. About $130 \mathrm{~s}$ were required to reach a new steady state concentration in the detector chamber for a flow rate of $333 \mathrm{~cm}^{3} / \mathrm{s}$. As the detector response reached a plateau, a reading was taken from the detector as well as a series of current readings from the EAA from which the concentration and size distribution were obtained. About $100 \mathrm{~s}$ were required for the EAA readings.

The same procedure was then repeated with another DOP solution of higher concentration, which means a larger particle size for the aerosol. For particle sizes greater than $0.5 \mu \mathrm{m}$, the aerosol flow from the detector test chamber was divided into two parts, one of which was collected on a filter and the other of which was diluted (50:1 to 500:1) and directed into the optical particle counter to determine the size distribution. For particle sizes of 0.5 and $0.7 \mu \mathrm{m}$, the EAA was also used for determining the number concentration but not for the particle size. Sixty seconds were required to obtain the size distribution using the optical particle counter together with the multichannel analyzer and 200$400 \mathrm{~s}$ were required to collect an adequate mass for the determination of the mass concentration.

Before testing another detector, both the atomizer and the evaporation condensation column were cleaned to remove the DOP.

\section{Results}

\subsection{Detector response}

Smoke detector responses minus the background readings are plotted versus number and mass concentration for various particle sizes in figures $8-20$. The responses of the light scattering type detectors were found in general to be proportional to the number concentration as determined by 
the EAA. As seen in figures 8,10 , and 12 , the responses of all three smoke detectors increase greatly with increasing particle size over the range 0.15 to $0.7 \mu \mathrm{m}$. The light scattering type detectors did not respond to particle sizes of 0.10 $\mu \mathrm{m}$ and less at concentrations as high as $3 \times 10^{6}$ particles/ $\mathrm{cm}^{3}$.

Because of the long collection time required in using the filter gravimetric method, the data for the mass concentration responses are much less extensive than for the number concentration. As seen in figures 9,11 , and 13 , for a fixed mass concentration the responses of the light scattering type detectors were found to depend only weakly on particle size over the range 0.5 to $1.3 \mu \mathrm{m}$. Detector $\mathrm{S}_{-}-1$

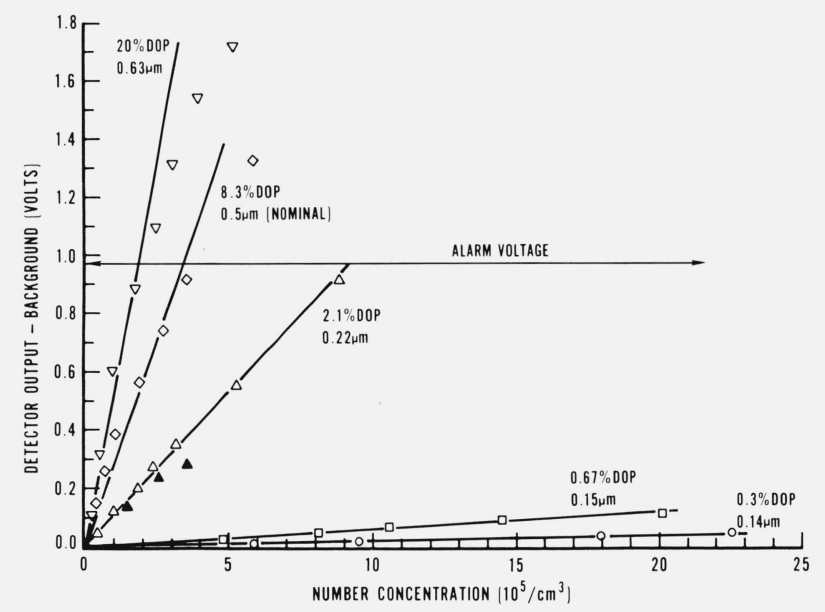

FIGURE 8. Response of detector $S-1$ is plotted versus particle concentration for monodisperse DOP aerosol.

The solid and open triangles represent repeat experiments several weeks apart. The alarm voltage corresponds to the detector signal when the detector is exposed to a polydisperse smoke with an optical density of $0.029 / \mathrm{m}(2 \%$ attenuation $/ \mathrm{ft})$.

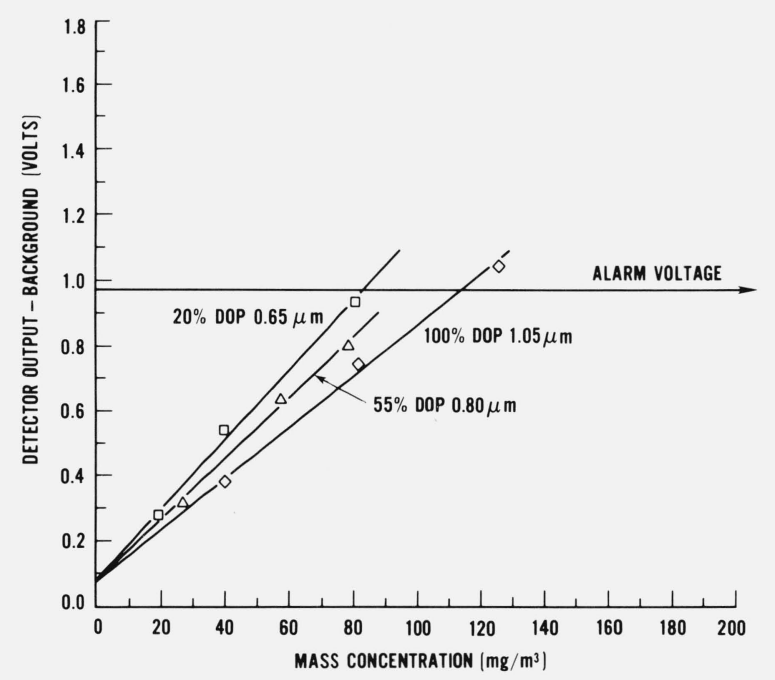

FIGURE 9. Response of detector $S-1$ is plotted versus mass concentration for monodisperse DOP aerosol.

The alarm voltage corresponds to the detector signal-when the detector is exposed to a polydisperse smoke with an optical density of $0.029 / \mathrm{m}(2 \%$ attenuation $/ \mathrm{ft})$. decreases slightly, S-2 remains almost constant, and S-3 apparently increases slightly in response with increasing particle size.

It was mentioned in section 4 that the teflon filters leak. The fact that the plots in figures 9,11 , and 13 intercept the ordinate axis at a positive value rather than at zero is an indication of a leak in the filter. Subsequent work involving simultaneous collection of the same aerosol with two different filters, one laminated teflon and the other unlaminated, verified that the laminated filter leaked.

The alarm voltages labeled in the figures correspond to the detector signal produced by a polydisperse smoke aerosol with an optical density of $0.029 / \mathrm{m}(2 \%$ attenuation $/ \mathrm{ft})$.

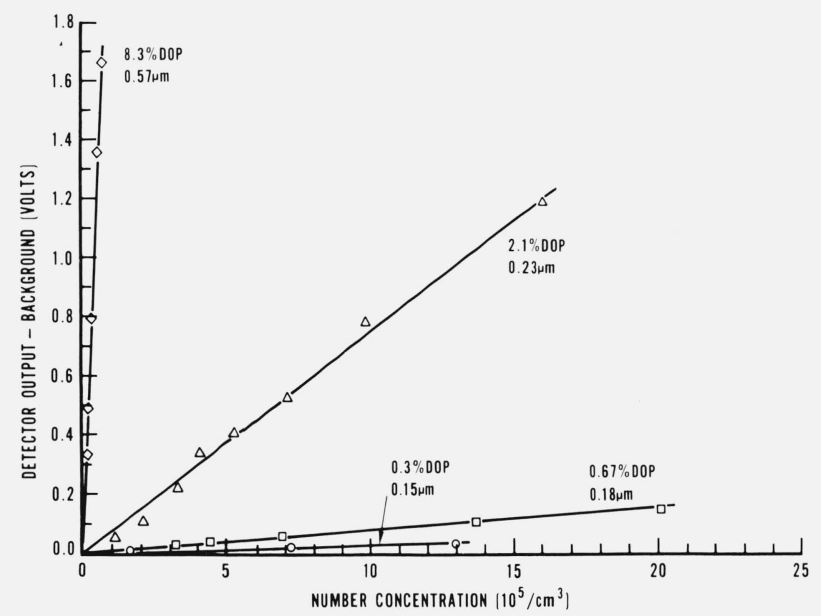

FIGURE 10. Response of detector $S-2$ is plotted versus number concentration for monodisperse DOP aerosol.

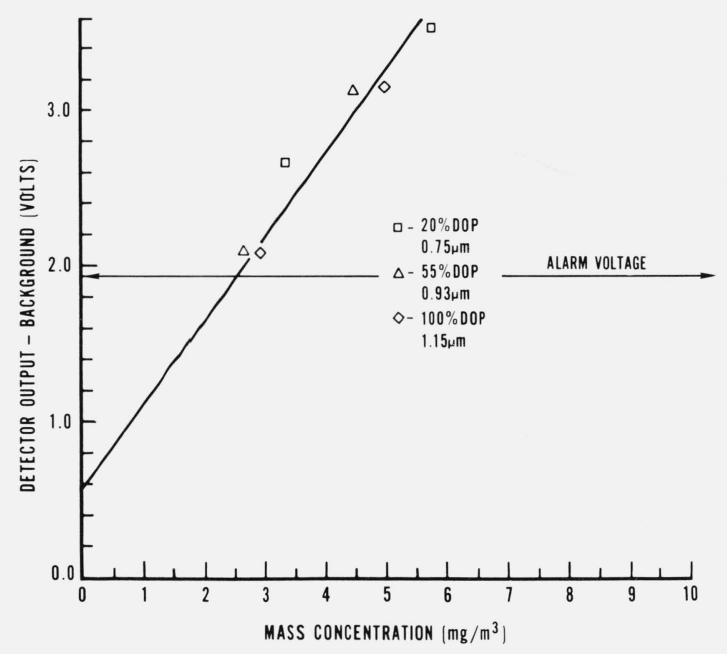

FIGURE 11. Response of detector $S-2$ is plotted versus mass concentration for monodisperse DOP aerosol.

The alarm voltage corresponds to the detector signal when the detector is exposed to a polydisperse smoke with an optical density of $0.029 / \mathrm{m}(2 \%$ attenuation $/ \mathrm{ft})$. 


$$
\text { Optical density }=\left(\log I_{0} / I\right) / L \text {, }
$$

where $I$ and $I_{0}$ are the intensities of the light beam with and without smoke present, respectively. This value corresponds to a nominal threshold value used by many manufacturers of smoke detectors. The difference in size sensitivity of detector S-2 and S-3 is striking. Extrapolating the line in figure 10 for the 2.1 percent DOP solution, one finds that on the order of $2.7 \times 10^{6}$ particles $/ \mathrm{cm}^{3}$ are required to reach the alarm voltage for detector S-2. For detector S-3 only

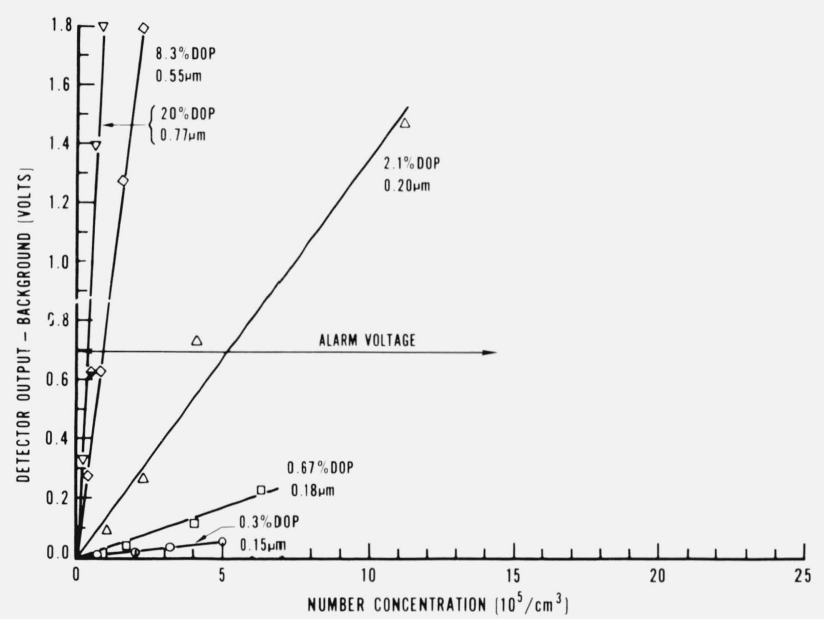

FIGURE 12. Response of detector $S-3$ is plotted versus number concentration for monodisperse DOP aerosol.

The alarm voltage corresponds to the detector signal when the detector is exposed to a polydis perse smoke with an optical density of $0.029 / \mathrm{m}(2 \%$ attenuation $/ \mathrm{ft})$.

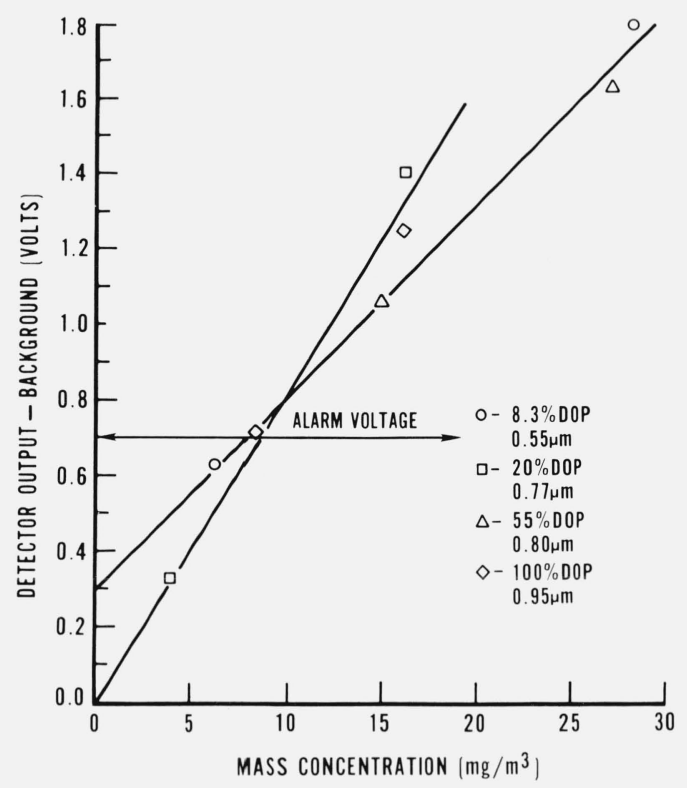

FIGURE 13. Response of detector $S-3$ is plotted versus mass concentration for monodisperse DOP aerosol.

The alarm voltage corresponds to the detector signal when the detector is exposed to a polydisperse smoke with an optical density of $0.029 / \mathrm{m}(2 \%$ attenuation $/ \mathrm{ft})$.
$7.5 \times 10^{5}$ particles $/ \mathrm{cm}^{3}$ are required to reach the alarm point. As the particles size increases, the situation reverses and $\mathrm{S}-2$ reaches the alarm threshold at a lower concentration than S-3. For example, from figures 11 and 13 it is seen that detector S-2 reaches its alarm threshold at a mass concentration of about $2.5 \mathrm{mg} / \mathrm{m}^{3}$ for the 20 percent DOP solution while detector $\mathrm{S}-3$ requires a mass concentration of $8 \mathrm{mg} / \mathrm{m}^{3}$ to alarm for the same solution concentration.

The responses of the ionization type detectors were also found to be proportional to number concentration and mass concentration. As seen in figures 14 to 19 , the responses of all three ionization smoke detectors increase with particle size for a fixed number concentration, though not as markedly as the light scattering type detectors; and the responses all decrease with increasing particle size for a fixed mass concentration. The ionization detectors were found to be sensitive to the smallest particles generated, $0.05 \mu \mathrm{m}$, while $0.15 \mu \mathrm{m}$ was the smallest particle size to which the light scattering type detectors were sensitive.

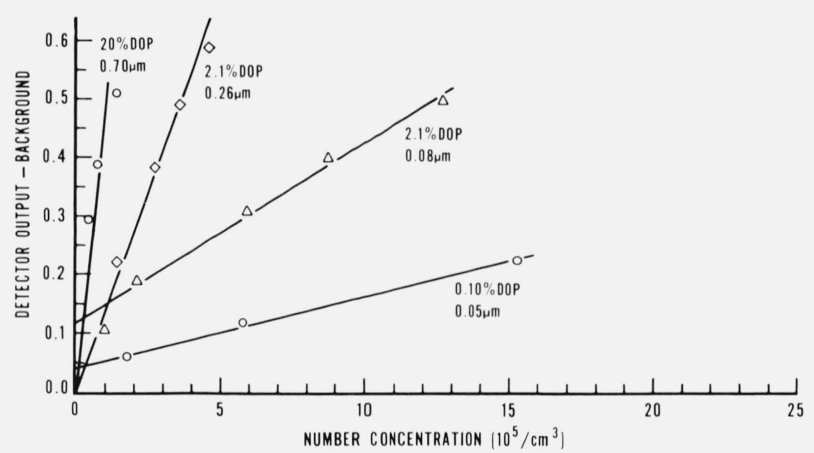

FIGURE 14. Response of detector $R-1$ is plotted versus number concentration for monodisperse DOP aerosol.

Interchanging the position of the scrubber and the evaporation-condensation column resulted in the smaller particle size for the data points represented by triangles.

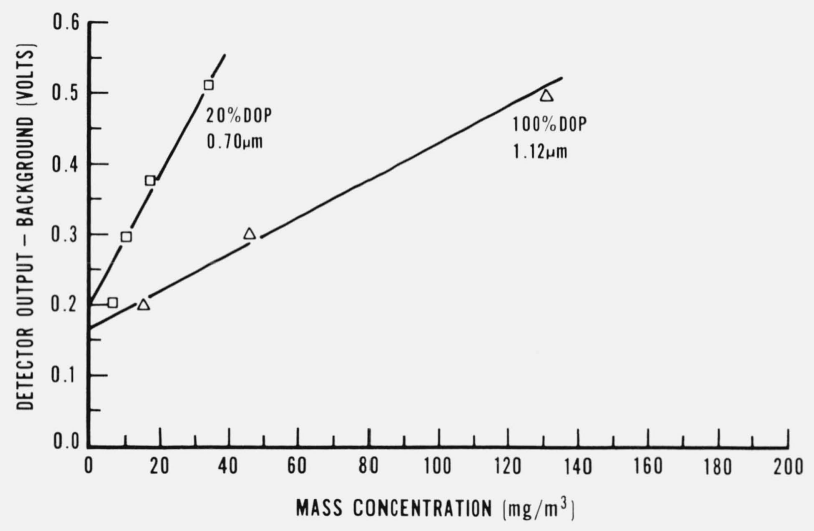

FIGURE 15. Response of detector $R-1$ is plotted versus mass concentration for monodisperse DOP aerosol. 


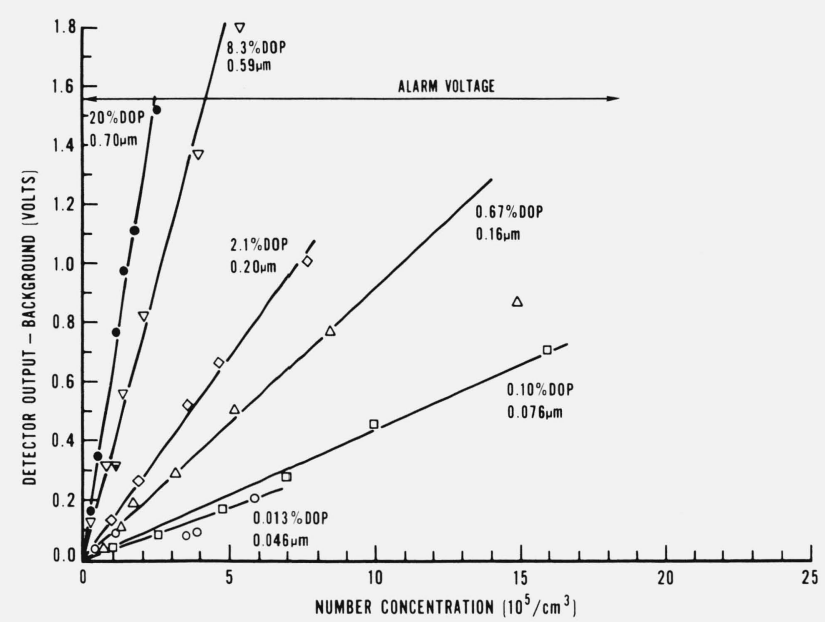

FIGURE 16. Response of detector $R-2$ is plotted versus number concentration for monodisperse DOP aerosol.

The alarm voltage corresponds to the detector signal when the detector is exposed to a polydisperse smoke with an optical density of $0.029 / \mathrm{m}(2 \%$ attenuation $/ \mathrm{ft})$.

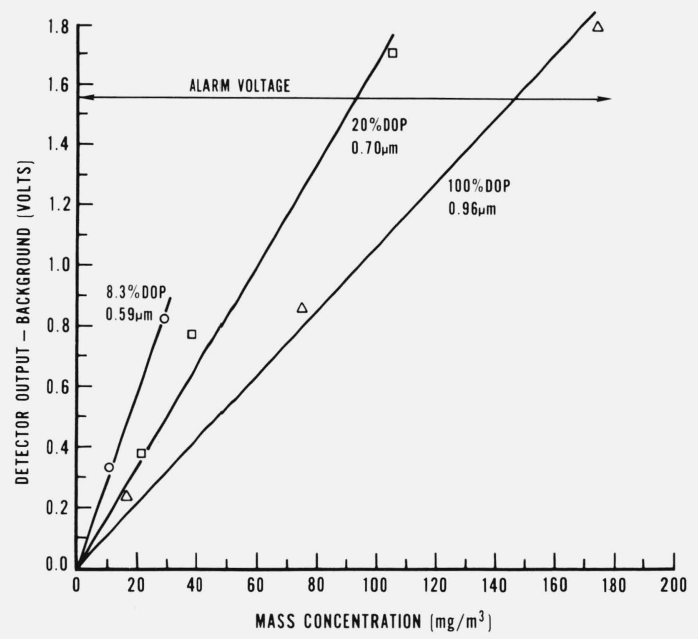

FIGURE 17. Response of detector $R-2$ is plotted versus mass concentration for monodisperse DOP aerosol.

The alarm voltage corresponds to the detector signal when the detector is exposed to a polydisperse smoke with an optical density of $0.029 / \mathrm{m}(2 \%$ attenuation $/ \mathrm{ft})$.

Generally speaking, the quality of the ionization detector data is not as high as that for the light scattering detectors. The aerosol generator itself is more difficult to control when testing the ionization detectors because of the additional components needed for scrubbing out the alcohol vapor and for controlling the humidity. Also the output from an ionization detector is intrinsically more noisy because of the

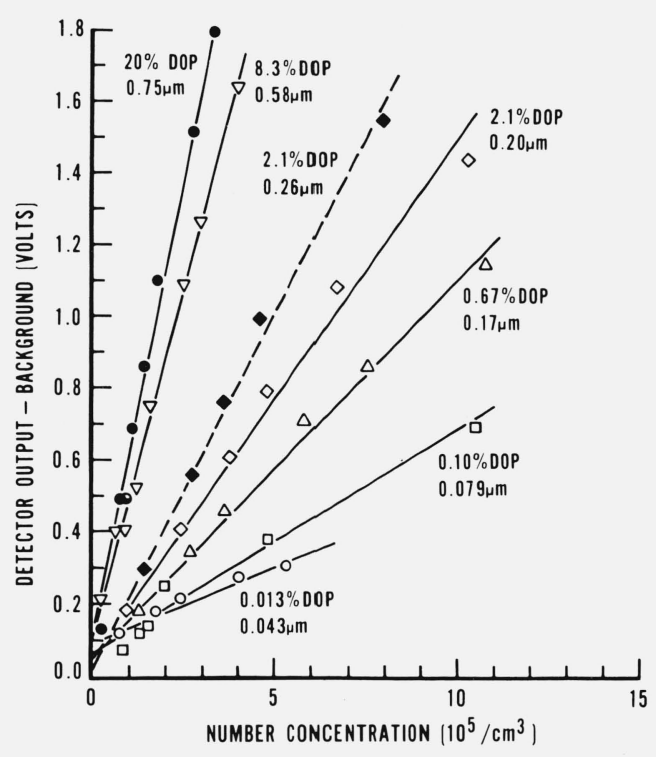

FIGURE 18. Response of detector $R-3$ is plotted versus number concentration for monodisperse DOP aerosol.

The solid and open diamonds represent repeat experiments several weeks apart.

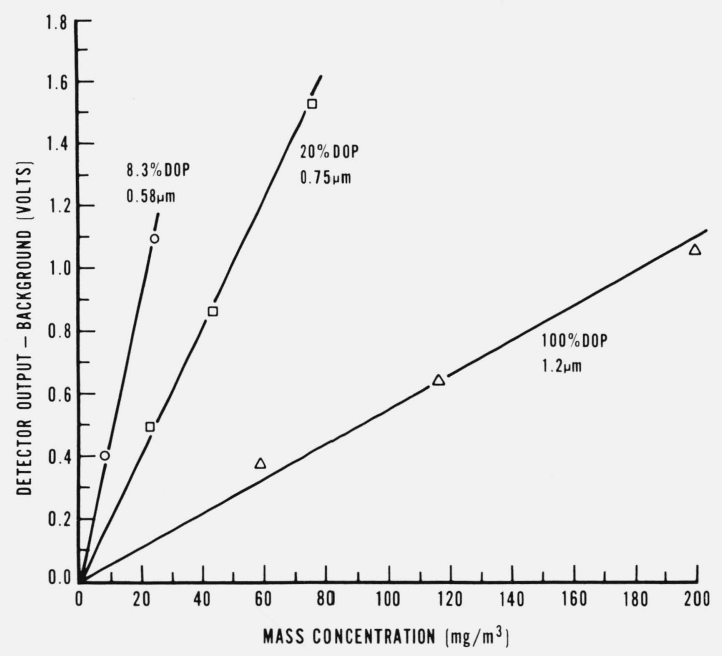

FIGURE 19. Response of detector $R-3$ is plotted versus mass concentration for monodisperse DOP aerosol.

stochastic nature of radioactive decay. The noise level for detector R-1 is approximately \pm 10 percent of the saturation value of the detector. The high noise level is partially a result of the low source strength for R-l compared to the other two ionization detectors tested. Representative strip chart recordings for R-1 and R-2 are given in figure 20 . 

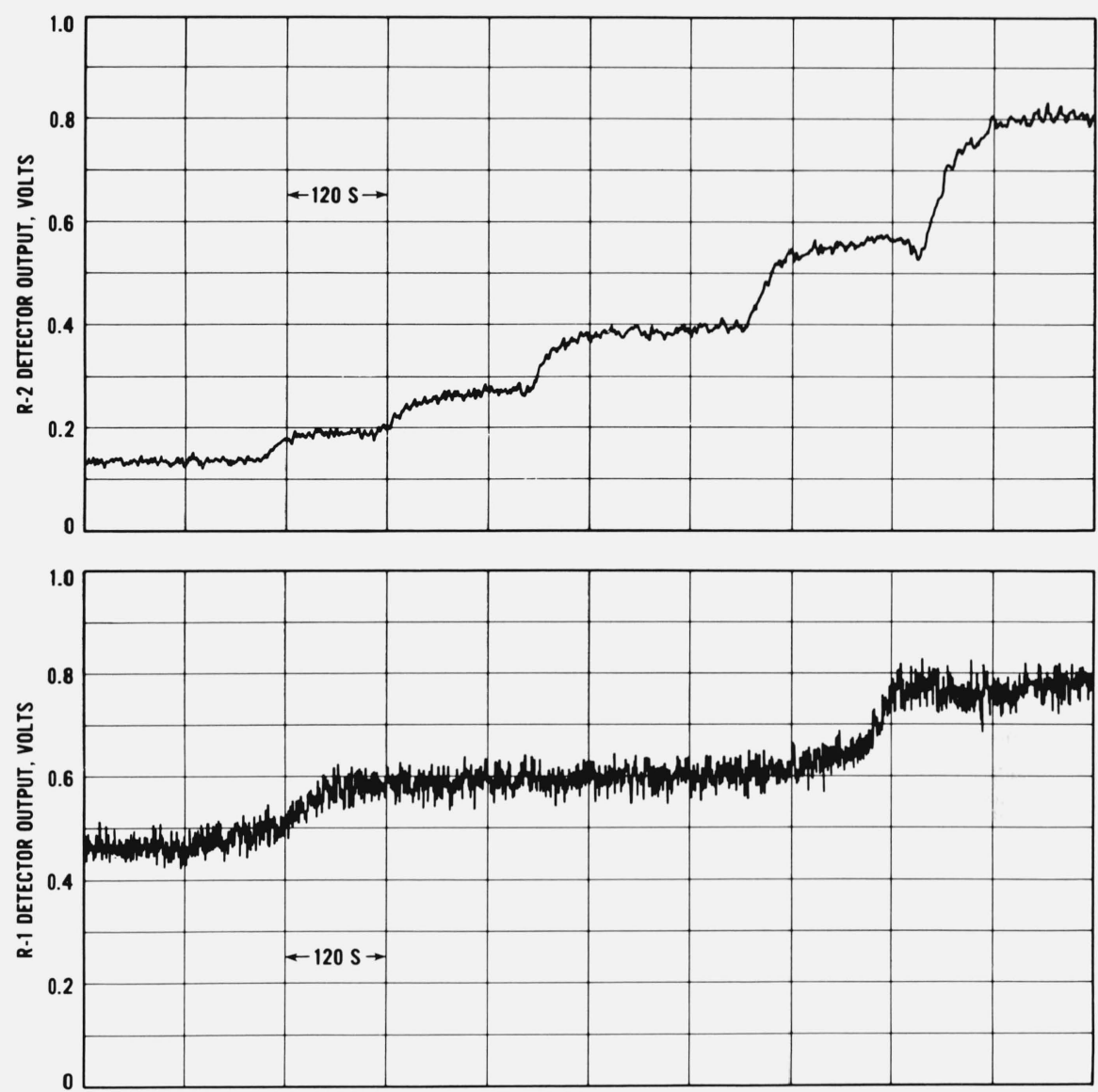

FIGURE 20. Signal outputs are displayed for detectors $R-1$ with a $1 \mu C i$-source and detector $R-2$ with a total source strength of $15 \mu \mathrm{Ci}$.

The chart recordings are from two separate experiments.

\subsection{Characterization of aerosol generation system}

In table 3 both the particle sizes measured in this study as well at the particle sizes determined by Liu and Lee [5] with a similar generator are given in terms of the geometric mean diameter defined by:

$$
\begin{aligned}
& k \\
& \Sigma \Delta n_{i} \log D_{\mathrm{i}} \\
& \log D_{g}=\frac{i=1}{k}, \\
& \Sigma \Delta n_{i} \\
& i=1
\end{aligned}
$$

where $k$ is the number of size classes, $\Delta n_{i}$ is the number of particles in the ith class, and $D_{i}$ is the particle size at the geometric midpoint of the size class. The variation in particle size was as large as 26 percent based on six separate experiments for $0.3 \mu \mathrm{m}$ DOP while the average percentage variation was 15 percent for the seven solution concentra- tions for which three or more sets of data were recorded. While the accuracy of the EAA for particle size measurements is on the order of \pm 20 percent, its precision is on the order of a few percent for the total concentration and it is able to resolve changes in particle size on the order of 5-10 percent. The resolution of the optical particle counter is even higher for detecting changes in particle size. The variation in particle size for a fixed concentration is thought to be caused by slight changes in the temperature of the evaporation-condensation column brought about by the air flow and temperature fluctuation in the laboratory and perhaps by the effect of DOP coating the column as the experiment progressed.

The measured particle size for the 8.3 percent solution is probably an overestimate of the true particle size, since the optical particle counter is not sensitive to particles with diameter less than $0.4 \mu \mathrm{m}$. The EAA, on the other hand, probably underestimates the particle size for the 0.67 percent and 2.1 percent DOP concentration due to the decreased sensitivity of the EAA for particle sizes over $0.3 \mu \mathrm{m}$. 
The geometric standard deviation, $\sigma_{g}$, defined by

$$
\log \sigma_{g}=\left[\begin{array}{l}
k \\
\sum\left(\log D_{i}-\log D_{g}\right)^{2} \Delta n_{i} \\
i=1 \\
k \\
\sum \Delta n_{i} \\
i=1
\end{array}\right]
$$

was found to be about 1.25 based on the optical particle counter. For the smallest particle size, $0.05 \mu \mathrm{m}, \sigma_{g}$ was found to be about 1.6 based on EAA measurements. The increase in spread is thought to result from nonvolatile impurities in the isopropanol.

\subsection{Repeatibility of experiments}

A limited number of duplicate experiments were made to test the repeatability of the measurements. Two sets of measurements on detector R-3 were made a month apart with the 2.1 percent DOP solution. The background reading with no DOP aerosol present had shifted by a small amount, $11.90 \mathrm{~V}$ to 12.00 , compared to a maximum response of about $2 \mathrm{~V}$ above the background. As seen in figure 18 for the 2.1 percent DOP solution, the slope of the line for the solid diamonds is noticeably larger than for the open symbols, $2.0 \times 10^{-6} \mathrm{~V} / \mathrm{cm}^{3}$ versus $1.4 \times 10^{-6} \mathrm{~V} / \mathrm{cm}^{3}$. It is thought that the steeper slope for the line with the solid diamonds is a result of the larger particle size, $0.26 \mu \mathrm{m}$, in this case compared to $0.20 \mu \mathrm{m}$ for the open diamonds. Somewhat better agreement was found between the two sets of measurements for $\mathrm{S}-1$ shown in figure 8 for the 2.1 percent DOP solution.

In general it appeared that the responses of the smoke detectors were not changed by exposure to the DOP aerosol. In all cases, the background readings before and after the tests were changed by at most 5 to 6 percent of the maximum reduced detector response. The largest source of variability in the tests was from the aerosol generator.

\subsection{Detector size response curve}

The fact that the detector outputs minus background readings are proportional to concentration enables one to define a concentration independent size response function, $R(D)$. A convenient definition for $R$ is detector output minus background reading divided by the number concentration.

$$
R(D)=\frac{\text { detector output }(\mathrm{V})-\text { background }(\mathrm{V})}{\text { number of particles } / \mathrm{cm}^{3}}
$$

The quantity $R(D)$ is expressed in terms of the units $\mu \mathrm{V} \mathrm{cm}$. For particle sizes of $0.7 \mu \mathrm{m}$ and less, the size response was obtained by dividing the analog detector signal minus the background reading by the number concentration as determined by the EAA. For example, $R(D)$ of detector S-l for $0.5 \mu \mathrm{m}$ DOP can be found from figure 8 by dividing the adjusted detector output, 0.56 volts, by the corresponding number concentration, $1.8 \times 10^{5}$ particles $/ \mathrm{cm}^{3}$, to yield 3.1 $\mu \mathrm{V} \mathrm{cm}{ }^{3}$. For each particle size, $R(D)$ is determined for three concentration levels and the range in the values is indicated by the error bars in figures 21 and 22 . Some of the uncertainty is due to the instability of the generator but part of it may also result from slight nonlinearity of the detector output with respect to concentration. The low level of the detec-

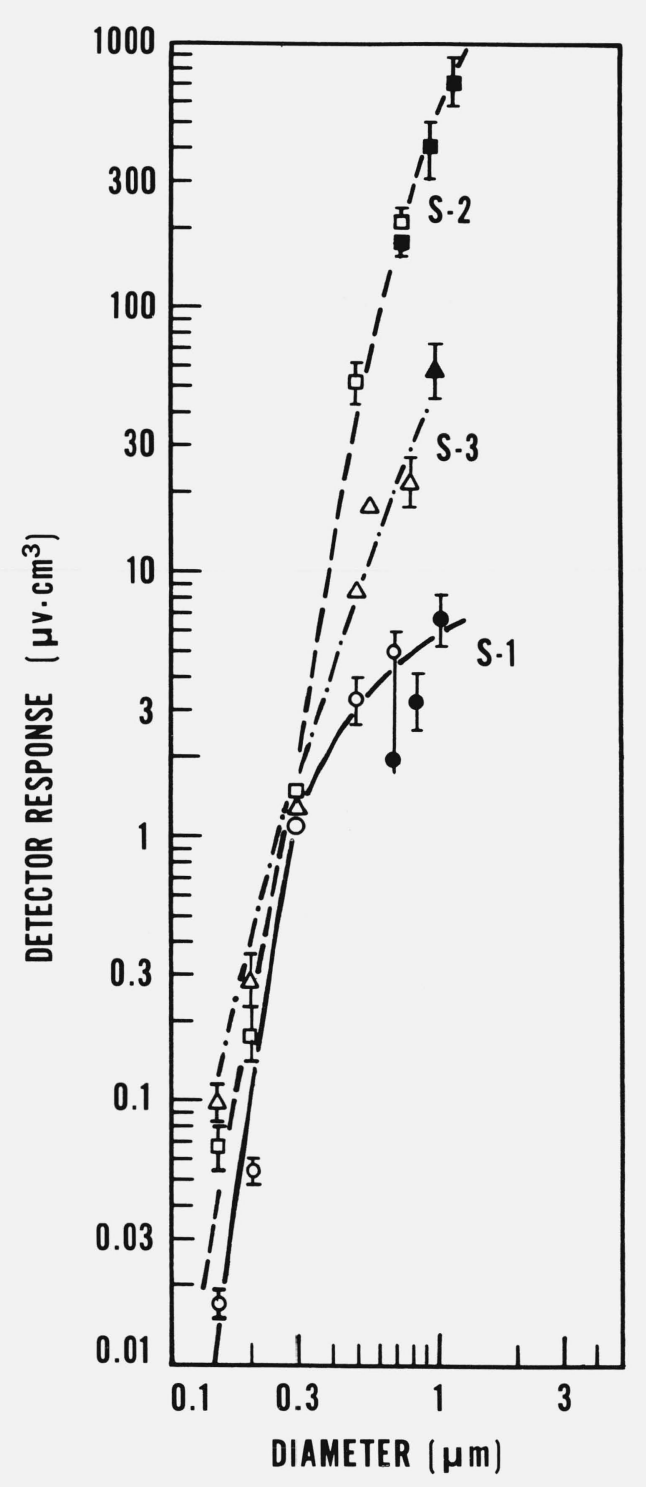

FIGURE 21. The size response function, $R(D)$, is plotted versus particle size for the light scattering detectors.

The open symbols refer to measurements by the electrical aerosol analyzer and the closed symbols refer to measurements made by the optical particle counter and filter gravimetric method. 


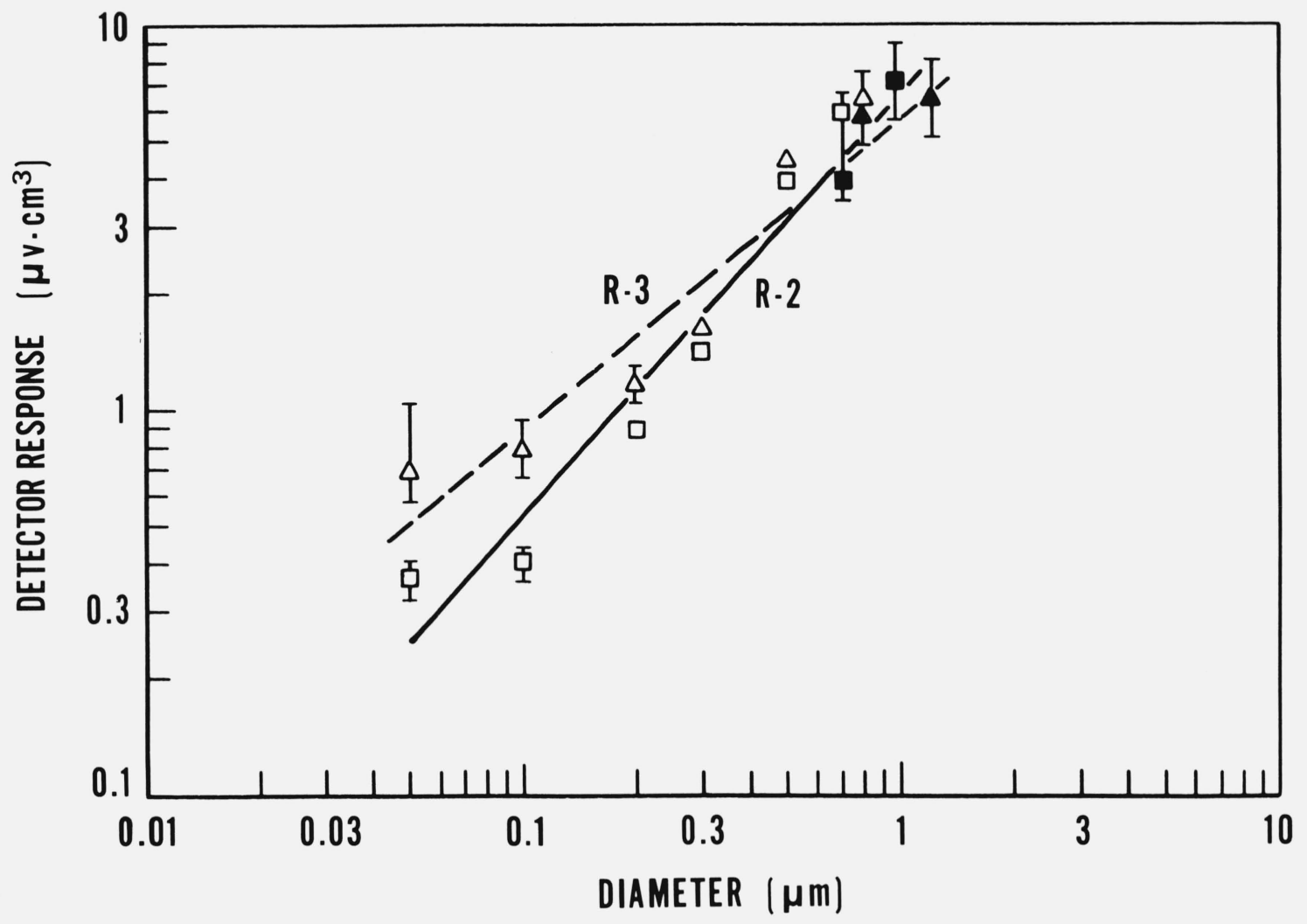

FIGURE 22. The size response function, $R(D)$, is plotted versus particle size for the ionization type detectors, $R-2$ ( $\square)$ and $R-3(\triangle)$.

The open symbols refer to measurements by the electrical aerosol analyzer and the closed symbols refer to measurements made by the optical partical counter and filter gravimetric method. The solid and dashed line represent the least square fit of the to a straight line for detectors R-2 and R-3 respectively.

tor signal is the cause of the large uncertainties for the ionization detector size response to the $0.05 \mu \mathrm{m}$ DOP and the light scattering detector size response to the $0.15 \mu \mathrm{m}$ DOP. For $0.3 \mu \mathrm{m}$ DOP, the average range in size response for five detectors is \pm 12 percent with the largest range of \pm 20 percent for S-3. Detector R-1 was not included in the compilation because of the high noise level and small dynamic range for the detector output.

For particle sizes of $0.7 \mu \mathrm{m}$ and larger, the number concentration was determined indirectly from the mass concentration and the size distribution of the diluted aerosol as measured by the optical particle counter using the following equation:

$$
N=\frac{6 m}{\pi \varrho D_{30}^{3}}
$$

where $m$ is the mass concentration in grams per cubic centimeter, $\varrho$ is the DOP density, and $D_{30}$ is the diameter of the particle whose volume is the arithmetic mean of all the particles volumes.

$$
D_{30}=\sqrt[3]{\frac{\sum_{i} D_{i}^{3} \Delta n_{i}}{\sum_{i} \Delta n_{i}}}
$$

The quantity $D_{30}$ is determined from the optical particle counter data. The quantity $D_{i}$ refers to the particle size at the geometric midpoint of the ith channel and $\Delta n_{i}$ is the number of particles in the ith channel. The six channels are equally spaced on a logarithmic scale, 0.15 units each, with the following midpoints: $0.42,0.59,0.84,1.19,1.68$, and $2.36 \mu \mathrm{m}$. The output from the mulitchannel analyzer was grouped into these six channels by use of the particle sizescattering strength calibration curve.

The number concentration was not determined directly from the optical particle counter because of the uncertainty in the dilution ratio between the aerosol going to the optical particle counter and that going to the detector. An uncertainty of \pm 10 percent in the determination of $D_{30}$ by optical particle counter results in a \pm 30 percent uncertainty in the number concentration, $N$, as is reflected by the error bars in figures 21 and 22 for particle sizes larger than $0.7 \mu \mathrm{m}$. 
There is also a systematic error in the derived number concentration resulting from aerosol leaking through the polyethylene backing of the teflon filters.

A comparison of the solid and open symbols in figures 21 and 22 provide a measure of the accuracy of the number concentration measurement. The solid symbols were determined by the procedure described above while the open symbols were determined by the EAA. It is seen that the discrepancy in the worst case is on the order of 50 percent with the average discrepancy about 20 percent.

\section{Discussion}

\subsection{Aerosol generation}

This study has demonstrated that the mechanical generation of an aerosol by nebulization followed by vaporization and condensation produces a monodisperse aerosol in the appropriate size and concentration range for studying smoke detector response. A significant feature of this generator is the production of a steady state aerosol stream with high stability over a period of an hour. In fact, the demonstrated high degree of stability of the mechanically generated aerosol has prompted the application of a nebulizer to the development of a smoke detector tester [9], which is currently being used for testing the sensitivity of installed smoke detectors.

\subsection{Light scattering detector}

In the limit of particle size small compared to the wavelength of light, the interaction of light with the particle may be treated as an electrical polarization within the particle resulting in an oscillating dipole moment. The intensity of the scattered light is calculated according to classical electro-magnetic theory. This type of scattering is called Rayleigh scattering and is given by the following formula for non-absorbing particles such as DOP [10]:

$$
I / I_{0}=\frac{\pi^{4}}{8}\left(\frac{n^{2}-1}{n^{2}+2}\right)^{2} \frac{D^{6}}{r^{2} \lambda^{4}}\left(1+\cos ^{2} \theta\right),
$$

where $n$ is the index of refraction, $\theta$ the scattering angle (figure 1), $D$ the particle diameter, $\lambda$ the wavelength, and $r$ the distance from the scatterer. It is known that this limit is realized for values of $D / \lambda<0.1$. This is slightly below the lower limit of the data obtained for the light scattering detector.

The analog outputs of the light scattering smoke detectors have a strong dependence on particle size for the smallest particle sizes - on the order of the fourth to fifth power of the particle diameter as seen in figure 21 -though somewhat less than the sixth power in particle diameter predict- ed for Rayleigh scattering. Detector S-3 with a wavelength of about $0.69 \mu \mathrm{m}$ is found to have a higher response at small particle sizes than detector S-2 with a wavelength of $0.94 \mu \mathrm{m}$. This is qualitatively consistent with Rayleigh scattering theory where the scattered intensity is inversely proportional to the fourth power of the wavelength. Quantitative comparison is not possible because of the lack of information regarding the relative electronic amplification for the two detectors. Also it is assumed in the comparison of theory and experiment that the analog detector output is proportional to the intensity of the scattered light. Detector S-l with a tungsten filiament light source can not be readily compared with the other detectors because of its broad wavelength spectrum.

The dipole approximation is no longer valid for particle sizes over a few tenths of a micrometer. The full solution of Maxwell's equations are required in the region $D / \lambda>0.1$. This region is called the Mie scattering region. One characteristic of the Mie regime is the enhanced scattering in the near forward direction. This is responsible for the much higher response of detector S-2 with a scattering angle of $21^{\circ}$ compared to S-3 with a scattering angle of $90^{\circ}$ for the large particle sizes. On the other hand as mentioned above the shorter wavelength of detector $\mathrm{S}-3,0.69 \mu \mathrm{m}$ vs $0.94 \mu \mathrm{m}$ for $\mathrm{S}-2$, is responsible for the greater response of S-3 for the small particle size range where Rayleigh scattering with its weak dependence on angle but strong dependence on wavelength is valid.

\subsection{Ionization detector}

The size responses for detectors R-2 and R-3 are plotted versus particle size in figure 22 . The data were not plotted for detector R-1 because of its limited dynamic range and its high noise level. As mentioned in the previous section, the size response function, $R(D)$, is determined for several concentration levels and the range in the values is indicated by the error bars. The average value of the $R(D)$ is used in the data analysis. The size response function can be correlated by a straight line on a log-log plot with particle diameter with a correlation coefficient of 0.98 for detector R-2 and 0.96 for detector $\mathrm{R}-3$. This indicates a power law relationship between detector response and particle size with the empirical relationship being:

$$
\begin{aligned}
& R(D)=6.7 D_{g}^{1.1}(\mathrm{R}-2) \\
& R(D)=5.8 D_{g}^{0.81}(\mathrm{R}-3),
\end{aligned}
$$

where $R$ is in units of micro-volts per particle concentration $\left(\mu \mathrm{V} \mathrm{cm}{ }^{3}\right)$.

The apparent leveling of the sensitivity for both detectors indicated in figure 22 for the smallest particle sizes must be 
considered as only suggestive because of the large experimental uncertainties arising from the weak detector signal from the $0.05 \mu \mathrm{m}$ particles. One conclusion that can be made from the data is that detector R-2 has a stronger dependence on particle size than does detector R-3.

Litton [11] has developed a mathematical model for the charge transfer in an ionization type smoke detector. He finds agreement within about 15 percent between his model and a simplified theory developed earlier by Hosemann [1]. Here the results of Hosemann's theory are presented because of the simplicity of his derived relationship between the ionization current, $I$, and the product of the number concentration and average particle size, $N \bar{D}$. For our purposes it is convenient to express this result in the following form:

$$
\frac{I_{0}-I}{I_{0}}=\frac{N \bar{D}}{2 \eta}+1-\sqrt{\left(\frac{N \bar{D}}{2 \eta}\right)^{2}+1}
$$

where $I_{0}$ is the ionization current in the absence of smoke and $\eta$ is the chamber constant defined by

$$
\eta=3 \frac{\sqrt{\alpha q}}{C} .
$$

In equation $11, \alpha$ is the recombination coefficient for ions in the chamber, $q$ is the ion generation rate from the radioactive material, and $C$ is the Bricard attachment coefficient equal to $0.3 \mathrm{~cm}^{2} \mathrm{sec}^{-1}$.

In the limit $\frac{N \bar{D}}{2 \eta}$ small compared to unity, one obtains the result that the current change is proportional to the product $N \bar{D}$.

$$
\frac{I_{0}-I}{I_{0}}=\frac{N \bar{D}}{2 \eta}, \frac{N \bar{D}}{2 \eta} \ll 1 .
$$

Experimentally it was found that the analog output of the detector minus the background reading had a similar dependence on the product $N \bar{D}$ as shown in figures 16 and 18 for the concentration dependence for fixed $\bar{D}$ and in figure 22 for the size dependence. A more detailed test of either ionization chamber theories would require a detector chamber with a simple geometric design such as parallel plates and the measurement of the ionization current directly rather than an indirect voltage measurement.

\subsection{Comparison of ionization and light scattering detectors}

The detector response function is plotted versus particle size for one ionization detector and one light scattering detector in figure 23. It is seen that for particle sizes smaller than about $0.3 \mu \mathrm{m}$ the ionization detector has the higher

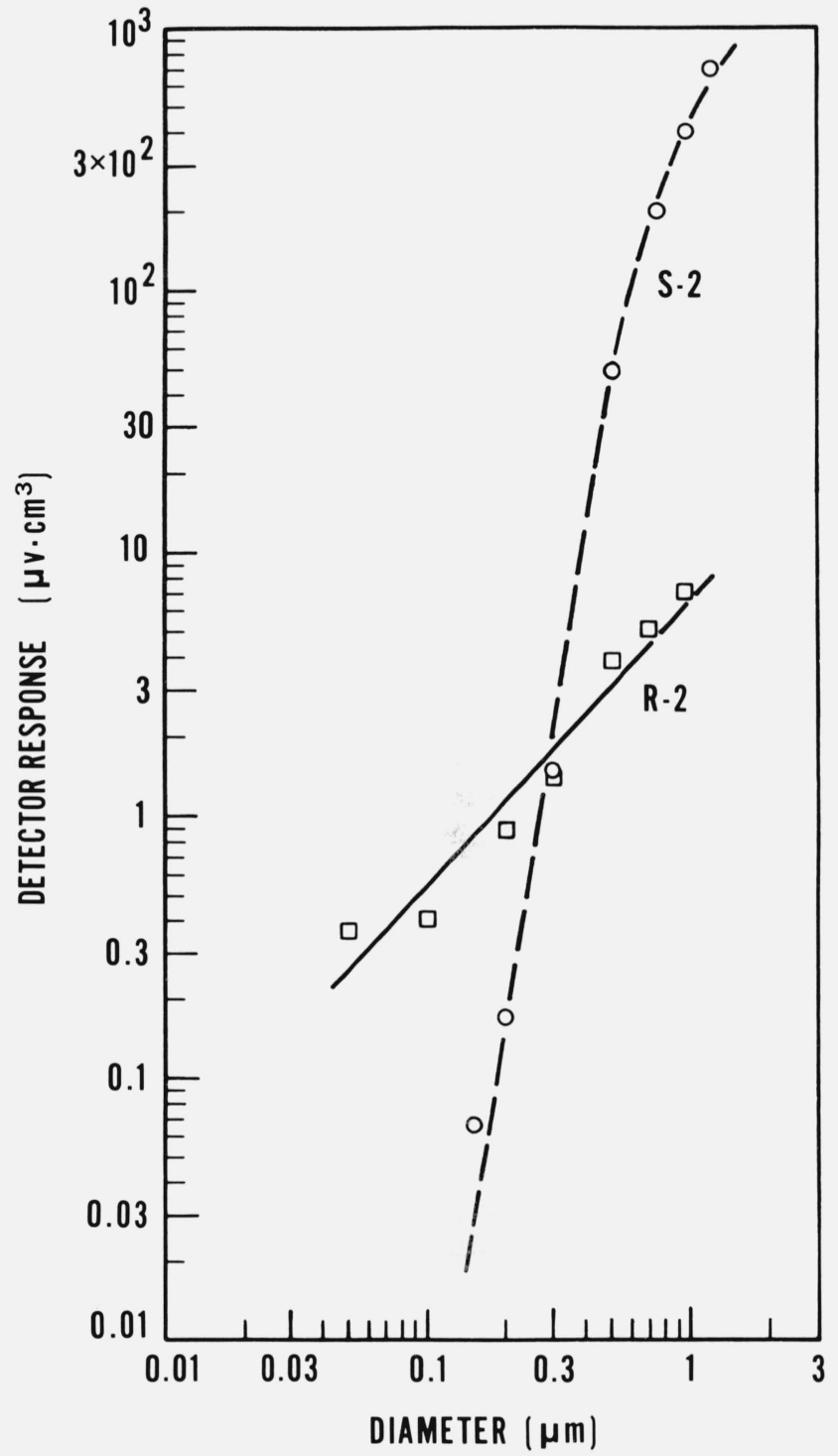

FIGURE 23. The size response function, $R(D)$, is plotted versus particle size for detectors $S-2$ (light scattering) and $R-2$ (ionization).

response, while for larger particle sizes the light scattering detector has the higher response. The exact position of the crossover point will depend on the electronic gain setting for the two detectors. Another way of comparing the two detectors is the number concentration of aerosol at which they reach the alarm point. As mentioned earlier, the alarm point is defined as the detector output voltage when exposed to a polydisperse smoke with an optical density of $0.029 / \mathrm{m}(2 \%$ attenuation $/ \mathrm{f})$. In the 2.1 percent DOP solution $(0.22 \mu \mathrm{m}), \mathrm{R}-2$ reaches the alarm point at less than half the concentration for $\mathrm{S}-2$; but for the 8.3 percent DOP solution $(0.58 \mu \mathrm{m}), \mathrm{R}-2$ requires four times the concentration to reach the alarm point compared to S-2. This demonstrates the strong dependence of detector response on particle size. 
This difference in the size response of the two types of smoke detectors is of some real concern. Small scale exeriments with flaming douglas fir, polyvinylchloride, and rigid urethane foam by Bankston et al [12] indicates that the peak particle size in terms of the mass size distribution, $d M / d \log D$, is in the range 0.1 to $0.3 \mu \mathrm{m}$. For such particle sizes the ionization detectors as a class are expected to be the more sensitive because of their higher sensitivity to small particles. The same materials burning under a smoldering or pyrolyzing mode generate particles with peak particle sizes in the range 0.5 to $1.5 \mu \mathrm{m}$. For such particle sizes, the light scattering detector is expected to be about as sensitive or more sensitive than the ionization detector depending on the full size distribution.

\section{Conclusions}

1. The mechanical generation of an aerosol followed by vaporization and condensation produces a monodisperse aerosol in the appropriate size and concentration range for studying smoke detector response.

2. For the concentration range extending up to the alarm point of the detectors, the ionization and light scattering detectors outputs were found to be linear functions of the number concentration for fixed particle size.

3 . The size response function, $R(D)$, was identified as a convenient way of characterizing the size response of a smoke detector.

4. The exponent characterizing the dependence of the ionization detector output on particle size was found to be within \pm 20 percent of Hosemann's predicted value of 1 for two detectors for the particle size range $0.05<D<$ $1.3 \mu \mathrm{m}$.

5. The light scattering detectors did not respond to particles less than about $0.1 \mu \mathrm{m}$ in diameter. The size response functions, $R(D)$, for the light scattering detectors as a class increase much more rapidly with particle size than $R(D)$ for the ionization detectors as a class and exceed in magnitude the value of $R(D)$ for the ionization detectors for a particle size of about $0.3 \mu \mathrm{m}$ and greater.

\section{References}

[1] Hosemann, J. P., Staub-Reinh alt. Luft 32, 13 (1972).

[2] Scheidweiler, A., Fire Technology, 113 (May, 1976).

[3] Lee, T. G. K. and Mulholland, G., NBSIR 77-1312 (Nov., 1977).

[4] Swiss Reactor Institute, An evaluation of the danger of the surroundings from ionization radiation and the radioactive sources of the Cerberus FES 6 fire detector.

[5] Liu, B. Y. H. and Lee, K. W., American Ind. Hyg. J. 36, 861 (1975).

[6] Liu, B. Y. H., Pui, D. Y. H. and Kapadia, A., in Aerosol Measurement, D. A. Lundgren et al., Eds., p. 341, (University of Florida Press, Gainesville, Florida, 1979).

[7] Mulholland, G. W., Pui, D. Y. H., Kapadia, A., and Liu, B. Y. H. Aerosol Number and Mass Concentration Measurements: A Comparison of the Electrical Aerosol Analyzer with Other Measurement Techniques, submitted to J. Colloid Interface Sci.

[8] Berglund, R. N. and Liu, B. Y. H., Environ. Sci. Technol. 7, 147 (1973).

[9] Lee, T. G. K., NBSIR 78-1430 (Feb. 1978).

[10] Hulst, Van de, Light Scattering by Small Particles, (John Wiley and Sons, Inc., New York, 1957).

[11] Litton, C. D., Fire Technology 13, 266 (1977).

[12] Bankston, C. P., Powell, E. A., Cassanova, R. A. and Zinn, B. T., J. Fire and Flamm. 8, 391 (1977).

This research was supported by the Center for Fire Research, National Bureau of Standards (Grant \#6-9005). The authors wish to thank the smoke detector industries for supplying the smoke detectors and for technical assistance. The authors thank Dr. David Y. H. Pui of the University of Minnesota for his assistance in setting up the aerosol generation system. 